\title{
Antioxidant Effects of Hydroxybenzalacetones on Peroxynitrite-Induced Lipid Peroxidation in Red Blood Cell Membrane Ghost and SOS Response in Salmonella typhimurium TA4107/pSK1002
}

\author{
Noriko Motohashi, ${ }^{* a}$ Ayumi TAKahashi, ${ }^{a}$ Chisako Yamagami, ${ }^{a}$ and Yutaka Saito ${ }^{b}$ \\ ${ }^{a}$ Kobe Pharmaceutical University; Motoyamakita-machi, Higashinada-ku, Kobe 658-8558, Japan: and ${ }^{b}$ Faculty of \\ Pharmaceutical Science, Okayama University; Tsushimanaka, Okayama 700-8530, Japan. \\ Received April 12, 2005; accepted May 10, 2005; published online May 16, 2005
}

\begin{abstract}
Antioxidant activity of a series of hydroxybenzalacetones was determined against peroxynitrite-induced lipid peroxidation in red blood cell membrane and SOS response through DNA damage in bacterial cells. Hydroxybenzalacetone derivatives with hydroxy, methoxy, ethoxy or methyl substitution were analyzed and found to be more effective than the water-soluble vitamin $E$ analogue Trolox. The inhibitory effect against lipid peroxidation correlated well to that against the SOS response, which is dependent on decomposition of peroxynitrite by hydroxybenzalacetones outside of the cell membrane. The antioxidant activity was shown to correlate well with the electric parameter $\sigma^{+}$. Electron-donating substituents with more negative $\sigma^{+}$values increased the potencies. The result suggests that hydroxybenzalacetones with more electron-donating substituents will protect tissue more effectively against oxidative stress.
\end{abstract}

Key words antioxidant effect; hydroxybenzalacetone; peroxynitrite; lipid peroxidation; SOS response; Salmonella typhimurium

Peroxynitrite is a strong biological oxidant that can be formed in vivo by the nearly diffusion-controlled reaction of nitric oxide and superoxide. ${ }^{1-3)}$ Peroxynitrite initiates lipid peroxidation, ${ }^{4)}$ damages DNA, ${ }^{5)}$ oxidizes thiol groups ${ }^{6,7)}$ and modifies amino acetyl groups on protein. ${ }^{8}$ The oxidation and damage induce various pathological conditions

We have reported that peroxynitrite induces the SOS response through DNA damage in the cells of Salmonella typhimurium TA4107/pSK1002 and that antioxidants added scavenge extracellular peroxynitrite. ${ }^{9}$ In addition, the SOS system was used for measuring the antioxidant potencies of manganese porphyrins against peroxynitrite, and tissue protection from oxidative stress was suggested. ${ }^{10)}$

Hydroxybenzalacetone derivatives (OH-BZs) are compounds related to dehydrozingerone and are regarded as 'half curcumin' (Fig. 1). Curcumin has been reported to be an antioxidant, and to have anti-inflammatory and antitumor-promoting activities. ${ }^{1-13)}$ We have investigated the potencies of $\mathrm{OH}-\mathrm{BZs}$ and we have reported the antimutagenic activities $^{14,15)}$ and antitumor-promoting activities. ${ }^{16,17)}$ We recently measured the inhibitory effects against lipid peroxidation by tert-butyl hydroperoxide $(t-\mathrm{BuOOH})$ and $\gamma$-irradiation and analyzed the quantitative structure-activity relationship. ${ }^{18)}$ In the present study, we measured the protective effects of $\mathrm{OH}$ BZs with a substituent(s) (Fig. 1) against lipid peroxidation and DNA damage in bacterial cells induced by peroxynitrite. Here we report that the antioxidant potencies against peroxynitrite increased with the electron-donating substituents,

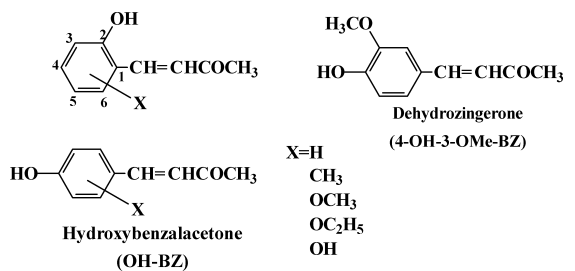

Fig. 1. Structures of the Hydroxybenzalacetone Derivatives Used and a linear relationship was observed between the electrondonating ability and activity.

\section{Experimental}

Chemicals Dehydrozingerone (4-OH-3-OMe-BZ) was purchased from Aldrich Chemical (WI, U.S.A.). Trolox was obtained from Tokyo Kasei (Tokyo, Japan). OH-BZs were synthesized by a modified method as described for 4-OH-BZ in ref. 19; reactions were performed at room temperature by using more dilute $\mathrm{NaOH}(10-20 \%)$ solutions. Peroxynitrite solution $\left(\mathrm{ONOO}^{-},>40 \mathrm{~mm}\right.$ in $\left.0.3 \mathrm{M} \mathrm{NaOH}\right)$ was from Dojindo (Kumamoto, Japan). The concentration of $\mathrm{ONOO}^{-}$was determined just before use by characteristic absorption at $302 \mathrm{~nm}$ in $0.1 \mathrm{M} \mathrm{NaOH}\left(\varepsilon=1670 \mathrm{M}^{-1} \mathrm{~cm}^{-1}\right){ }^{20)}$ 2-Thiobarbituric acid (TBA), $o$-nitrophenyl- $\beta$-D-galactopyranoside (ONPG) and ampicillin were obtained from Wako Pure Chemicals (Osaka, Japan). All other chemicals were of the highest grade available. All solutions were prepared with deionized water from Barnstead ultra pure water system.

Preparation of Red Blood Cell (RBC) Membrane Ghost RBC membrane ghosts were prepared using commercially available rabbit blood as described previously. ${ }^{10)}$ RBCs washed with PBS were lysed in $10 \mathrm{~mm}$ phosphate buffer with 0.1 mM EDTA, pH 7.4. After the lysed solution was centrifuged, the precipitate was washed with $10 \mathrm{~mm}$ phosphate buffer and suspended in $10 \mathrm{~mm}$ phosphate buffer. The RBC membrane ghost suspension was diluted to give $2.0 \mathrm{mg}$ protein $/ \mathrm{ml}$ and frozen as aliquots at $-80^{\circ} \mathrm{C}$ until use.

Measurement of $\mathrm{ONOO}^{-}$-Induced Lipid Peroxidation Lipid peroxidation by $\mathrm{ONOO}^{-}$was monitored colorimetrically measuring TBA-reactive substances produced in the RBC membrane ghost. ${ }^{10)}$ The reaction mixture $(500 \mu \mathrm{l})$ contained RBC membrane ghost suspension $(100 \mu \mathrm{l}), \mathrm{OH}-\mathrm{BZ}$ solution $(100 \mu \mathrm{l})$ and $0.067 \mathrm{~mm}$ phosphate buffer, $\mathrm{pH} 6.8(300 \mu \mathrm{l})$. The peroxidation was initiated by adding $\mathrm{ONOO}^{-}(30 \mathrm{~mm}, 5 \mu \mathrm{l})$ and terminated by $\mathrm{HCl}$ $(0.05 \mathrm{M}, 1 \mathrm{ml})$ after $30 \mathrm{~min}\left(37^{\circ} \mathrm{C}\right)$. The reaction mixture with $0.67 \%(\mathrm{w} / \mathrm{v})$ TBA solution added $(0.5 \mathrm{ml})$ was heated at $95^{\circ} \mathrm{C}$ for $15 \mathrm{~min}$, cooled rapidly and mixed with $n$-butanol containing $15 \%(\mathrm{v} / \mathrm{v})$ methanol solution $(1.5 \mathrm{ml})$. After centrifugation $(1400 \times \boldsymbol{g}, 15 \mathrm{~min})$, the supernatant was measured at $535 \mathrm{~nm}$. The amount of the TBA-reactive substances produced was calculated using a calibration curve for tetramethoxypropane as a malondialdehyde standard.

Measurement of $\mathrm{ONOO}^{-}$-Induced SOS Response The strain $S$. typhimurium TA4107/pSK1002 (oxy $\Delta l[$ oxy $\Delta($ oxyR $\operatorname{argH}) 1] /$ umuC'-'lacZ) was used for induction of SOS response by $\mathrm{ONOO}^{-9}{ }^{9}$ ) The fused gene (umuC'-'lacZ) is induced through the SOS response by DNA damage and results in a hybrid protein with $\beta$-galactosidase activity. ${ }^{21)}$ The overnight cell culture was diluted 20-fold with TGA (1\% Bacto tryptone, $0.5 \% \mathrm{NaCl}$ and $0.2 \%$ glucose) medium with $20 \mu \mathrm{g} / \mathrm{ml}$ ampicillin and incubated to $\mathrm{OD}_{600}=0.25-0.3$ at $37^{\circ} \mathrm{C}$. The cells were resuspended into PBS 

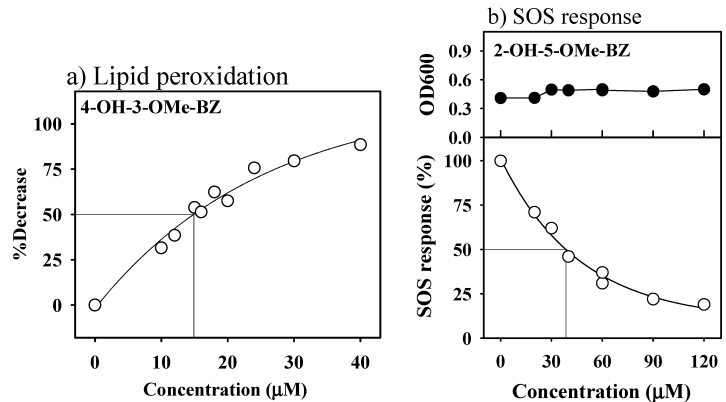

Fig. 2. Determination of $\mathrm{IC}_{50}$ of 4-OH-3-OMe-BZ and 2-OH-5-OMe-BZ against Oxidation by $\mathrm{ONOO}^{-}$

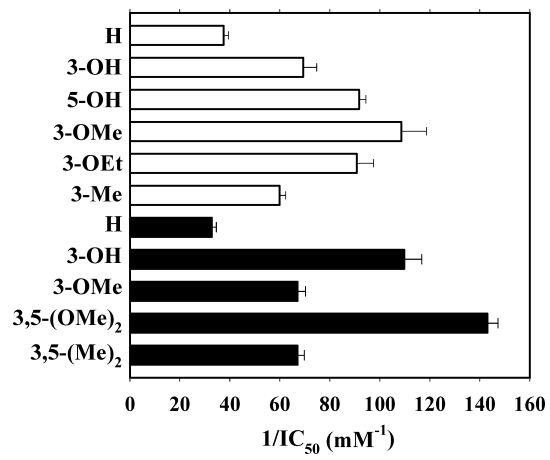

Fig. 3. Inhibitory Effects of $\mathrm{OH}-\mathrm{BZ}$ s on $\mathrm{ONOO}^{-}$-Induced Lipid Peroxidation

Open and closed bars represent 2-OH-BZs and 4-OH-BZs, respectively.

$\left(\mathrm{OD}_{600}=1.0-1.2\right)$. The various concentrations of $\mathrm{OH}-\mathrm{BZ}$ s and PBS $(50 \mu 1)$ were added to the sample tubes and the controls $(0.45 \mathrm{ml}$ each $)$, respectively. Following the preincubation, the induction of the SOS response was initiated by addition of $\mathrm{ONOO}^{-}(30 \mathrm{~mm}, 5 \mu \mathrm{l})$ and incubated at $37^{\circ} \mathrm{C}$ for $30 \mathrm{~min}$. After centrifugation, the cells in TGA $(2.5 \mathrm{ml})$ were incubated for another $90 \mathrm{~min}$. The $\beta$-galactosidase activity was calculated using the following equation: units $=1000\left(\mathrm{OD}_{420}-1.75 \mathrm{OD}_{550}\right) /\left(t(30 \mathrm{~min}) \times v(0.2 \mathrm{ml}) \times \mathrm{OD}_{600}\right){ }^{9)}$

Calculation of $50 \%$ Inhibition $\left(\mathrm{IC}_{50}\right)$ against Lipid Peroxidation and SOS Response The antioxidant activities of OH-BZs were examined by their $\mathrm{IC}_{50}$ values, the concentrations that inhibit $50 \%$ of the lipid peroxidation induced by $\mathrm{ONOO}^{-}$. The value was calculated using the equation from a nonlinear regression for the relationship between the concentrations used and the percentage of the TBA-reactive substances induced (Fig. 2a). The $\mathrm{IC}_{50}$ value against the DNA damage was obtained from the relationship between the concentrations used and the percentage of the SOS response produced (Fig. 2b). All data are expressed as mean \pm S.D. of three or more experiments.

\section{Results and Discussion}

Figure 3 shows the inhibitory effects of OH-BZs with substituents at 3- and/or 5-position in the lipid peroxidation. Three $(\mathrm{OH})_{2}$-BZs, 2,3-, 2,5- and 3,4-substituted derivatives, exhibited $2-3$ times the inhibitory effects of 2-OH-BZ and 4-OH-BZ, indicating that the introduction of an $\mathrm{OH}$ group into the ortho- or para-position(s) of the phenolic $\mathrm{OH}$ group increased the antioxidant potencies. In addition, the presence of 3-alkoxyl group strengthened the activity by about $2-3$ times. In 4-OH-BZs, the activity of $4-\mathrm{OH}-3,5-(\mathrm{OMe})_{2}-\mathrm{BZ}$ with two ortho-methoxy groups was about twice that of 4$\mathrm{OH}-3-\mathrm{OMe}-\mathrm{BZ}$, suggesting that the substituent effect is additive. Taking into account this additivity rule, the effects of the ortho substituent on the activity would be in the order $\mathrm{OH}>\mathrm{OMe}>\mathrm{Me}$.

Table 1 shows $\mathrm{IC}_{50}$ values of $\mathrm{OH}-\mathrm{BZs}$ against lipid peroxi-
Table 1. $\mathrm{IC}_{50}$ Values of $\mathrm{OH}-\mathrm{BZs}$ against $\mathrm{ONOO}^{-}$-Induced Lipid Peroxidation and SOS Response

\begin{tabular}{cccc}
\hline \hline & \multicolumn{2}{c}{$\mathrm{IC}_{50}(\mu \mathrm{M})$} & \\
Compound & \multirow{2}{*}{$\sigma^{+a)}$} \\
\cline { 2 - 3 } & Lipid peroxidaton & SOS response & \\
\hline 2-OH-BZ & & & \\
H & $26.7 \pm 1.4$ & $87.9 \pm 4.2$ & 0 \\
3-OH & $14.4 \pm 1.1$ & $17.7 \pm 1.0$ & -0.98 \\
5-OH & $10.9 \pm 0.32$ & $9.89 \pm 0.68^{c)}$ & -0.98 \\
3-OMe & $9.21 \pm 0.85$ & $35.5 \pm 0.7$ & -0.78 \\
4-OMe & $25.4 \pm 0.9$ & $51.8 \pm 1.4$ & 0.05 \\
5-OMe & $12.5 \pm 1.1$ & $38.5 \pm 1.3$ & -0.78 \\
3-OEt & $11.0 \pm 0.8$ & $24.9 \pm 0.9$ & -0.78 \\
3-Me & $16.7 \pm 0.7$ & $42.4 \pm 2.5$ & -0.31 \\
5-Me & $21.6 \pm 1.2$ & $51.7 \pm 2.7$ & -0.31 \\
4-OH-BZ & & & \\
H & $30.5 \pm 1.7$ & $108 \pm 6$ & 0 \\
3-OH & $9.11 \pm 0.58$ & $17.7 \pm 1.5$ & -0.98 \\
3-OMe & $14.9 \pm 0.7$ & $53.3 \pm 4.8$ & -0.78 \\
3,5-(OMe $)_{2}$ & $6.99 \pm 0.21$ & $22.8 \pm 1.5$ & $-1.56^{b)}$ \\
3,5-(Me $)_{2}$ & $14.9 \pm 0.6$ & $47.4 \pm 1.5$ & $-0.62^{b)}$ \\
Trolox & $48.6 \pm 2.3$ & $57.0 \pm 5.1$ & - \\
\hline
\end{tabular}

The reaction mixture contained $0.2 \%$ DMSO. Lipid peroxidation and SOS response were induced by $0.3 \mathrm{~mm} \mathrm{ONOO}^{-}$. a) The data was obtained from refs. 22,23 . b) $2 \sigma_{o}^{+} . \quad$ c) The compound was toxic for cells.

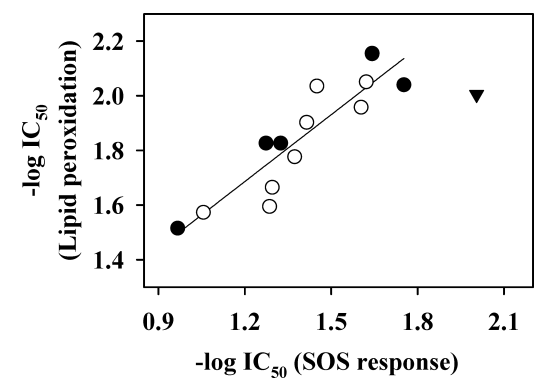

Fig. 4. Correlation between $-\log \mathrm{IC}_{50}$ Values of Lipid Peroxidation and SOS Response

Open and closed circles represent 2-OH-BZs except 2,5-(OH) - -BZ (triangle, toxic) and 4-OH-BZs, respectively. Correlation coefficient $=0.903(n=13)$.

dation and SOS response induction by $\mathrm{ONOO}^{-}$. Benzalacetone (BZ), a non-phenolic compound, reduced neither peroxidation nor SOS response (data not shown). In the lipid peroxidation, all of $\mathrm{OH}-\mathrm{BZ}$ s tested inhibited the peroxidation more strongly than Trolox, a water-soluble analog of vitamin $\mathrm{E}$, and in the SOS response, OH-BZs except 2-OH-BZ and 4$\mathrm{OH}-\mathrm{BZ}$ were stronger than Trolox. 2,5-(OH) $-\mathrm{BZ}$ showed the strongest inhibition against the SOS response, but was toxic for bacterial cells. The inhibitory effects $\left(-\log \mathrm{IC}_{50}\right)$ on the lipid peroxidation and the SOS response showed a good correlation ( $r=0.903)$ except $2,5-(\mathrm{OH})_{2}$-BZ (Fig. 4).

We previously investigated the quantitative structure-activity relationship for the inhibitory effect against the lipid peroxidation by $t$-BuOOH and $\gamma$-irradiation, ${ }^{18}$ showing that the electronic parameter, $\sigma^{+}{ }^{22)}$ which involves through-resonance effects, plays an important role in describing the potency $\left(-\log \mathrm{IC}_{50}\right){ }^{23)}$ The values of $\sigma^{+}$represent the electronic effects of the substituents on the phenolic $\mathrm{OH}$ group, and the $\sigma_{p}^{+}$values were used as the $\sigma_{o}^{+}$values of the corresponding ortho-substituent $\left(\sigma_{p}^{+}=\sigma_{o}^{+}\right)$because the effect of the ortho-substituent is supposed to be equivalent with that of the para-substituent. ${ }^{24)}$ By using this assumption, the rela- 


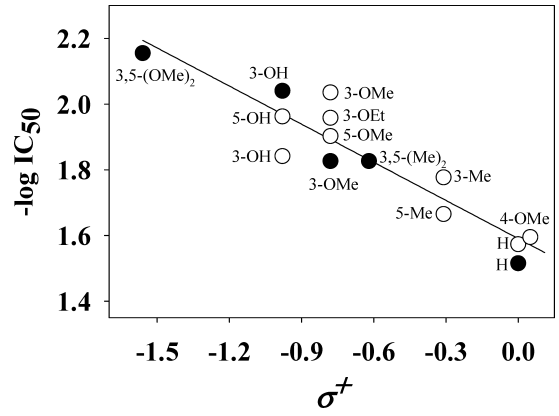

Fig. 5. Correlation between Electronic Parameter $\sigma^{+}$and $-\log \mathrm{IC}_{50}$ of $\mathrm{OH}-\mathrm{BZs}$ against $\mathrm{ONOO}^{-}$-Induced Lipid Peroxidation

Open and closed circles represent 2-OH-BZs and 4-OH-BZs, respectively. Correlation coefficient $=0.930(n=14)$.

tionship between $-\log \mathrm{IC}_{50}\left(\mathrm{ONOO}^{-}\right)$and $\sigma^{+}$was examined, led to a good correlation $(r=0.930)$ as shown in Fig. 5. The activity increased as the $\sigma^{+}$value becomes more negative, showing that more electron-donating substituents increase the antioxidant activity. In Fig. 5, all compounds showing positive deviations from the regression line are those with ortho substituents. This would mean that the ortho steric effect would even strengthen the activity. On the other hand, the $-\log \mathrm{IC}_{50}$ value of the lipid peroxidation was hardly correlated to the hydrophobicity parameter $\log P(1.3-2.7){ }^{26)}$ In the SOS response, a poor correlation was also observed. The results suggest that the OH-BZs tested should not create a significant hydrophobic interaction with $\mathrm{RBC}$ ghosts and the bacterial cell membrane. Similar results were observed for the antioxidant activities of OH-BZs against lipid peroxidation induced by $t$ - $\mathrm{BuOOH}$ and $\gamma$-iradiation, although the $\mathrm{OH}-\mathrm{BZs}$ tested contained derivatives of wider range of hydrophobicity $(1.3<\log P<4.0){ }^{18)}$ Moreover, Nakao et al. has demonstrated that no hydrophobic contribution is involved in the inhibitory activities of hydroxyphenylurea derivatives against lipid peroxidation of rat brain homogenate. ${ }^{27)}$

In conclusion, the OH-BZs tested here inhibited the oxidation of membrane lipids and the DNA damage of bacterial cells induced by peroxynitrite. Both oxidation systems were inhibited by OH-BZs more effectively than with Trolox, mainly depending on the electron-donating effect. OH-BZs with substituents of more negative $\sigma^{+}$values increased the activities in the same way as observed in the inhibitory effects on lipid peroxidation by $t$-BuOOH and $\gamma$-irradiation. ${ }^{18)}$ The inhibitory activities of OH-BZs against the DNA damage were dependent on the peroxynitrite-scavenging potency just outside cells because antioxidants react with extracellular peroxynitrite and the DNA damage is induced by peroxy- nitrite through the cell membrane without decomposition. ${ }^{9)}$ The results suggest that the OH-BZs tested here will protect tissue under oxidative conditions.

Acknowlegements The authors are grateful to Dr. Yoshimitu Oda for providing the bacterial strain. This work was supported in part by a Grantsin Aid for Scientific Research (15590105) from the Ministry of Education, Culture, Sports, Science and Technology of Japan.

\section{References and Notes}

1) Beckman J. S., Beckman T. W., Chen J., Marshall P. A., Freeman B. A., Proc. Natl. Acad. Sci. U.S.A., 87, 1620-1624 (1990).

2) Koppenol W. H., "Metal Ions in Biological Systems," Vol. 36, ed. by Siegel H., Marcel Dekker, New York, 1999, pp. 597-619.

3) Kissner R., Nauser T., Bugnon P., Lye P. G., Koppenol W. H., Chem. Res. Toxicol., 10, 1285-1292 (1997).

4) Radi R., Beckman J. S., Bush K. M., Freeman B. A., Arch. Biochem. Biophys., 288, 481-487 (1991).

5) Douki T., Cadet J., Ames B. N., Chem. Res. Toxicol., 9, 3-7 (1996).

6) Radi R., Beckman J. S., Bush K. M., Freeman B. A., J. Biol. Chem., 266, 4244-4250 (1991).

7) Quijan C., Alvarez B., Gatti R. M., Augusto O., Radi R., Biochem. J., 322, 167-173 (1997).

8) Daiber A., Mehl M., Ullrich V., Nitric Oxide, 2, 259-269 (1998).

9) Motohashi N., Saito Y., Mutat. Res., 502, 11-18 (2002).

10) Motohashi N., Takahashi A., Mifune M., Saito Y., Mutat. Res., 554, $165-174$ (2004).

11) Masuda T., Jitoe A., Isobe J., Nakatani N., Yonemori S., Phytochemistry, 32, 1557-1560 (1993).

12) Osawa T., Sugiyama Y., Inayoshi M., Kawakishi S., Biosci. Biotech. Biochem., 59, 1609-1612 (1995).

13) Ruby A. J., Kuttan G., Babu K. D., Rajasekharan K. N., Kuttan R., Cancer Lett., 94, 79-83 (1995).

14) Motohashi N., Ashihara Y., Yamagami C., Saito Y., Mutat. Res., 377, 17-25 (1997).

15) Motohashi N., Ashihara Y., Yamagami C., Saito Y., Mutat. Res., 474, 113-120 (2001).

16) Motohashi N., Yamagami C., Tokuda H., Konoshima T., Okuda Y., Okuda M., Mukainaka T., Nishino H., Saito Y., Cancer Lett., 134, 37-42 (1998).

17) Motohashi N., Yamagami C., Tokuda H., Okuda Y., Okuda M., Ichiishi E., Mukainaka T., Nishino H., Saito Y., Mutat. Res., 464, 247-254 (2000).

18) Yamagami C., Motohashi N., Emoto T., Hamasaki A., Tanahashi T., Nagakura N., Takeuchi Y., Bioorg. Med. Chem. Lett., 14, 5629-5633 (2004).

19) Buck J. S., Heilbron I. M., J. Chem. Soc., 121, 1095-1101 (1922).

20) Hughes M. N., Nicklin H. G., J. Chem. Soc. A, 1968, 450-452 (1968).

21) Oda Y., Nakamura S., Oki I., Kato T., Shinagawa H., Mutat. Res., 147, 219-229 (1985).

22) Brown H. C., Okamoto Y., J. Am. Chem. Soc., 80, 4979-4987 (1958).

23) Stock L. M., Brown H. C., Adv. Phys. Org. Chem., 1, 35-154 (1963).

24) Fujita T., Nishioka T., Prog. Phys. Org. Chem., 12, 49-89 (1976).

25) Hansch C., Gao H., Chem. Rev., 97, 2995-3059 (1997).

26) Yamagami, unpublished results.

27) Nakao K., Shimizu R., Kubota H., Yasuhara M., Hashimura Y., Suzuki T., Fujita T., Ohmizu H., Bioorg. Med. Chem., 6, 849-868 (1998). 